\title{
Correspondence
}

\author{
Vascular Endothelial Growth Factor, Transforming \\ Growth Factor- $\alpha$, and Estrogen Receptors: \\ Possible Cross-Talks and Interactions
}

\section{To the Editor-in-Chief:}

Recently, we read with special interest the paper published by Graubert et al ${ }^{1}$, concerning the modulation of vascular endothelial growth factor (VEGF) during the menstrual phases. The authors made several statements regarding the VEGF mRNA levels in endometrial stromal cell cultures submitted to different estrogen and progesterone in vitro treatments. They concluded that hypoxia induced a 2.4-fold increase in VEGF mRNA levels by 48 hours of exposure, estrogen and progesterone stimuli slightly raised the VEGF mRNA levels, and no decrease in VEGF mRNA was observed after withdrawal of the estrogen and progesterone. ${ }^{1}$ In addition, the authors also infer that it is unlikely that steroids play a direct role on VEGF regulation, a view that is controversial, and in contrast with our findings in breast epithelial cells. ${ }^{2,3}$

We have been studying the effects of estrogen and progesterone in the expression of VEGF mRNA and protein using a human breast cancer cell line, MCF-7 (ATCC). Briefly, after culturing MCF-7 breast cancer cell line for 48 hours with $17 \beta$-estradiol $1 \times 10^{-9} \mathrm{~mol} / \mathrm{L}$ (Sig$\mathrm{ma}$ ) or progesterone $1 \times 10^{-8} \mathrm{~mol} / \mathrm{L}$ (Sigma), we evaluated the expression of mRNA and protein levels of angiogenic factors, namely VEGF, by RT-PCR and Western blotting, respectively. Whereas Graubert et al ${ }^{1}$ observed only a slight increase in VEGF transcript after estrogen stimulation, our preliminary results demonstrate that, somehow, estrogen induces VEGF overexpression, both in mRNA and protein levels. In accordance with our results, a recent report showed the presence of estrogen response elements in VEGF gene promotor region, ${ }^{4}$ indicating that estrogens are, in fact, involved in VEGF upregulation.

In the last two years, several papers concerning the different patterns of estrogen receptor (ER) $\alpha$ and $\beta$ expression by epithelial, stromal, and vascular endothelial endometrial cells have been published. ${ }^{5-8}$ Mueller et $\mathrm{al}^{15}$ and Lecce et $\mathrm{al}^{6}$ showed a highly complex pattern of $\alpha$ and $\beta$ receptor distribution during the menstrual cycle. It has been shown that ER- $\alpha$ and ER- $\beta$ mRNA levels in the eutopic endometrium were affected by a cycle change in ovarian hormones. ${ }^{7}$ We would be interested in knowing the estrogen receptor profile of those stromal endometrial cells during the cell culture, since no basal tonus hormonal stimulation was maintained during the experiment, or at least it is not shown.
This might lead to a down-regulation of the estrogen receptors, since their expression is transient during the menstrual cycle and is highly dependent on the estrogen, progesterone, luteinizing hormone, and follicle stimulating hormone levels. ${ }^{7,8} \mathrm{~A}$ distinct pattern of ER among breast and endometrium tissues would also explain the discrepancy between the Graubert et $\mathrm{al}^{1}$ results and ours. It is also known that different ER modulators (both ER coactivators and corepressors) are differentially expressed within different organs, which would lead to different responses after estrogen stimulus.

Conversely, the authors showed a moderate increase in VEGF mRNA levels after progesterone treatment; ${ }^{1}$ these findings are very similar to what we observed in MCF7 in vitro experiments. VEGF is involved in proliferation and migration of vascular endothelial cells. Since progesterone is mainly synthesized during endometrial secretory phase, this steroid hormone is likely to mediate the growth and maintenance of stable coiled arterioles that characterize this phase, through the activation of growth factors other than VEGF.

Moreover, these authors did not find any increase in mRNA levels of TGF- $\alpha$ and IL-1 $\beta$ when the endometrial cells were submitted to hypoxic stimulus. ${ }^{1}$ We also evaluated the hypoxic effects in MCF-7 cultures using a different model (hypoxia-like effect induced by $\mathrm{CoCl}_{2}$ added to culture medium). Despite the differences in our model and the one used by the authors, ${ }^{1}$ our results were very similar concerning the TGF- $\alpha$ mRNA and protein levels. In fact, TGF- $\alpha$ expression was not induced by hypoxic conditions in MCF-7 cells.

Our group has previously reported that TGF- $\alpha$, a growth factor activated by estrogen, ${ }^{2,3}$ associated with higher angiogenic rates in a series of 86 invasive breast cancer cases. ${ }^{2,3}$ Since ER- $\alpha$ is the predominant activated isotype in breast tissue, and in agreement with TGF- $\alpha$ driven VEGF up-regulation reported by Graubert et $\mathrm{al}^{1}$ in stromal endometrial cells, we can hypothesize that ER- $\alpha$ activated on estrogen stimulus might promote TGF- $\alpha$ expression, which up-regulates VEGF. This putative mechanism defines a relevant role of estrogen in angiogenic switch. However, further studies are needed to reach a conclusive model of ER- $\alpha$, ER- $\beta$, TGF- $\alpha$, and VEGF crosstalk.

Raquel Soares Jorge S. Reis-Filho

Fatima Gartner

University of Porto

Fernando C. Schmitt

Porto, Portugal 


\section{References}

1. Graubert MD, Ortega MA, Kessel B, Mortola JF, Iruela-Arispe ML: Vascular repair after menstruation involves regulation of vascular endothelial growth factor-receptor phosphorylation by sFLT-1. Am J Pathol 2001, 158:1399-1410

2. Schmitt FC, Soares R: TGF- $\alpha$ and angiogenesis. Am J Surg Pathol 1999, 23:358-359

3. Schmitt FC, Soares R: Hormonal control of angiogenesis in breast cancer: TGF- $\alpha$, a missed link? The Breast 1999, 8:154-156

4. Hyder S, Nawaz Z, Chiappetta C, Stancel GM: Identification of functional estrogen response elements in the gene coding for the potent angiogenic factor VEGF. Cancer Res 2000, 60:3183-3190

5. Mueller MD, Vigne JL, Minchenko A, Lebovic DI, Leitman DC, Taylor RN: Regulation of vascular endothelial growth factor (VEGF) gene transcription by estrogen receptors alpha and beta. Proc Natl Acad Sci USA 2000, 97:10972-10977

6. Lecce G, Meduri G, Ancelin M, Bergeron C, Perrot-Applanat M: Presence of estrogen receptor beta in the human endometrium through the cycle: expression in glandular, stromal, and vascular cells. J Clin Endocrinol Metab 2001, 86:1379-1386

7. Matsuzaki S, Uehara S, Murakami T, Fujiwara J, Funato T, Okamura K: Quantitative analysis of estrogen receptor alpha and beta messenger ribonucleic acid levels in normal endometrium and ovarian endometriotic cysts using a real-time reverse transcription-polymerase chain reaction assay. Fertil Steril 2000, 74:753-759

8. Critchley HO, Brenner RM, Henderson TA, Williams K, Nayak NR, Slayden OD, Millar MR, Saunders PT: Estrogen receptor beta, but not estrogen receptor alpha, is present in the vascular endothelium of the human and non-human primate endometrium. J Clin Endocrinol Metab 2001, 86:1370-1378

\section{Authors' Reply:}

We thank the group at the University of Porto (Portugal) for their interest in our work and for bringing to discussion some important aspects related to regulation of VEGF by steroids, a much-debated issue.

In our recently published manuscript ${ }^{1}$ we described consistent, but modest, increases in VEGF mRNA levels under culture conditions when exposed to steroids. This was contrasted by the effect of hypoxia and other cytokines (IL-1 and TGF- $\alpha$ ), which elevated VEGF mRNA nearly 10-fold. Results from Northern blots of total endometrial tissue using human subjects with hormonal determination of cycle stage revealed that overall VEGF mRNA is significantly increased upon menstruation, a time when both estrogen and progesterone levels are lowest and hypoxia is highest. The combination of these results and much validation from in vitro experiments supported our general conclusion that "it is unlikely that sex steroids play a significant role on VEGF regulation during postmenstrual repair as circulating estrogen and progesterone levels are physiologically low at this point in the cycle" (Am J Pathol 158:1408). If one is to focus attention on the proliferative and secretory phases, results from our Northern analysis support that VEGF is increased by 1.6and 1.8-fold, respectively, considering 1-fold levels in early proliferative phase. Whether steroids alone are responsible for these increases requires further investigation.

More revealing and pertinent to the discussion at hand are results from in situ hybridization. Evaluation of VEGF transcripts in the endometrium of women during the pro-
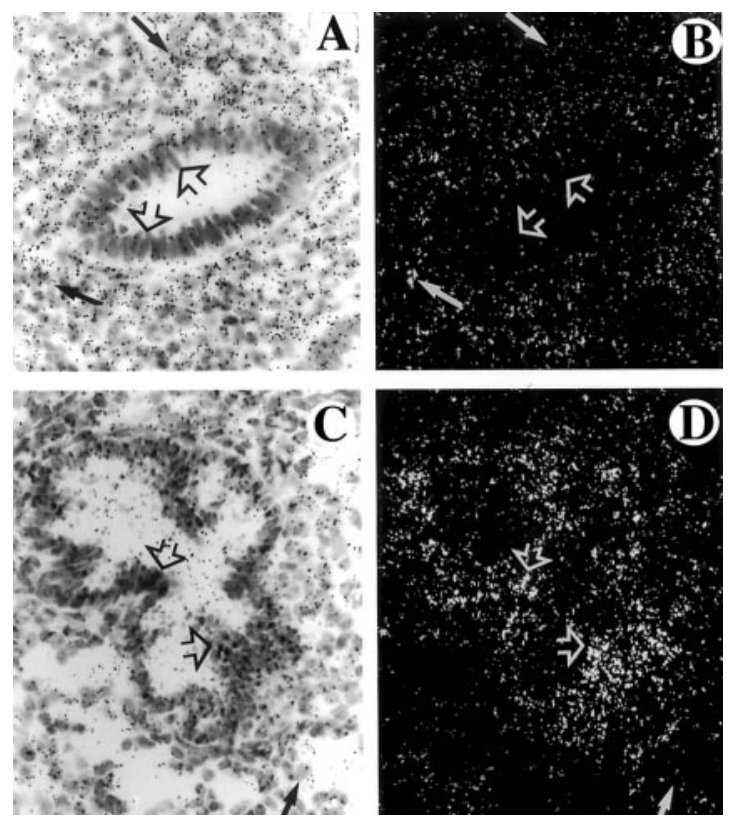

Figure 1. Localization of VEGF mRNA in human endometrium during late proliferative (A and $\mathbf{B}$ ) and late secretory $(\mathbf{C}$ and $\mathbf{D})$ stages. Shown are paired bright-field and dark-field photomicrographs of the same microscopic field. Epithelial cells from glands are indicated with open arrows. Stromal endometrial cells are indicated with closed arrows

liferative phase showed low levels in the glands (Figure 1 $A$ and $B$, open arrows) and higher expression in the stroma (closed arrows). In contrast, secretory endometrium showed strong transcript levels in the glands (open arrows) with light expression in the stroma (C and D, closed arrows). These results were not included in our manuscript because the major conclusions have been previously published by another group using immunocytochemistry, but with identical results. ${ }^{2}$ The take-home message is that different cellular compartments respond differently to the same hormonal levels. Naturally it is the combination of multiple signaling pathways and their integration that results in variations of transcript levels. We feel that keeping this in mind is essential for interpretation of in vitro data.

The group of Porto reports unpublished information using MCF-7 cells. We do not argue with their findings. In fact, increases of VEGF by estradiol has been reported by several groups (a brief evaluation shows 12 published papers centered on this subject alone). Our overall assessment from working on this problem and closely following the literature is that different cells will respond differently to similar signals and this appears to be the case with VEGF. In addition, in vivo validation is essential to ascertain the biological relevance of in vitro findings. In this light, in a recent publication in AJP, using the VEGF promoter linked to GFP might prove to be of extreme value. ${ }^{3}$ Not to be repetitive, we would like to direct interested readers on the subject to a well put together commentary by Drs. Sengers and Van De Water ${ }^{4}$ on that same issue.

Finally, thanks to the editorial panel of The American Journal of Pathology for providing us with the opportunity to present our response and to Dr. Larry Brown (Depart- 
ment of Pathology, BIDMC, Boston, MA) for allowing to use his in situ data as part of this response.

Luisa Iruela-Arispe

University of California Los Angeles

Los Angeles, California

Palmetto Fertility Center of South Florida

Michael D. Graubert

Miami, Florida

\section{References}

1. Graubert MD, Ortega MA, Kessel B, Mortola JF, Iruela-Arispe ML: Vascular repair after menstruation involves regulation of vascular endothelial growth factor receptor. Am J Pathol 2001, 158:1399-1410

2. Zhang L, Scott PA, Turley H, Leek R, Lewis CE, Gatter KC, Harris AL, Mackenzie IZ, Rees MC, Bicknell R: Validation of anti-vascular endothelial growth factor (anti-VEGF) antibodies for immunohistochemical localization of VEGF in tissue sections: expression of VEGF in the human endometrium. J Pathol 1998, 185:402-408

3. Kishimoto J, Ehama R, Ge Y, Kobayashi T, Nishiyama T, Detmar M, Bugerson RE: In vivo detection of human vascular endothelial growth factor promoter activity in transgenic mouse skin. Am J Pathol 2000, 157:103-110

4. Senger DR, Van De Water L: VEGF expression by epithelial and stromal cell compartments: resolving a controversy. Am J Pathol 2000, 157:1-3

\section{Accurate Gene Expression Measurement in Formalin-Fixed and Paraffin-Embedded Tumor Tissue}

\section{To the Editor-in-Chief:}

In the February 2001 issue of The American Journal of Pathology, Specht and colleagues ${ }^{1}$ have published technical advances in their article entitled "Quantitative Gene Expression Analysis in Microdissected Archival FormalinFixed and Paraffin-Embedded Tumor Tissue." In contrast to earlier published data, where RNA extraction and subsequent RT-PCR from formalin-fixed and paraffin-embedded tissue (FFPE) has been reported to be cumbersome, ${ }^{2}$ Specht et al $^{1}$ present an optimized protocol for RNA extraction from FFPE tissue, followed by the powerful TaqMan quantitative RT-PCR methodology. ${ }^{3}$ Major improvement of RNA extraction is achieved by prolonged proteinase $\mathrm{K}$ digestion at $60^{\circ} \mathrm{C}$. In addition, the choice of very short amplicons, tolerating a high degree of RNA degradation, represents a major breakthrough.

In a different system, we have observed a high tolerance of TaqMan measurements towards RNA degradation. Human colon tissue was incubated at room temperature from 10 minutes up to 4 hours prior to RNA extraction. At up to 90 minutes, incubation at room temperature revealed no detectable degradation of RNA as indicated by a ratio of $28 \mathrm{~S}: 18 \mathrm{~S} \geq 2$ evaluated by the RNA 6000 LabChip kit with the Agilent 2100 Bioanalyzer. Degradation was observed after 120 minutes by a decreased ratio of $28 \mathrm{~S}: 18 \mathrm{~S}$ of 1.4 . Thereafter, the ratio further de- creased to zero and accumulation of short RNA fragments was detected. However, the quantitative determination of the amount of GAPDH, $\beta$-actin, c-Myc, and Fra-1 expression using the TaqMan technology did not alter over the complete time range. Amplified amplicons were 69 to 83 base pairs in size. ${ }^{4}$

Specht et $\mathrm{al}^{1}$ have chosen an HT29 and A431 xenograft model to test relative gene expression of various genes in adjacent lying frozen and FFPE tumor halves. Whereas several genes showed no difference in expression levels as compared between frozen and FFPE, the levels of FGF-R4 and of EGF-R varied significantly. These differences seem to occur in a non-predictable manner. On the other hand, we observed a clear gene expression difference in tissues with low-quality RNA (eg, FFPE) compared to frozen tissue, especially when genes with low expression levels were compared.

Furthermore, Specht et $\mathrm{al}^{1}$ have tested the influence of tissue thickness on fixation and RNA degradation. They stated that in tissue thickness of up to $7 \mathrm{~cm}$ no differences of RNA expression levels were found, irrespective of whether measurements were carried out at either the surface or at pre-defined levels $(1 \mathrm{~cm}, 2 \mathrm{~cm}$, etc.) inside the tissue. A rule of thumb states that tissue thickness should not exceed $5 \mathrm{~mm}$ in at least in one spatial dimension to allow proper fixation. ${ }^{5}$ However, the authors do not indicate whether the given tissue thickness addresses all three dimensions (eg, $7 \times 7 \times 7 \mathrm{~cm}^{3}$ ) or only one. Therefore, it remains speculative whether the presented data reflect an unfavorable or a rather favorable fixation condition.

Laser microdissection represents a powerful tool to study gene expression in a histomorphological context. The opportunity to investigate archival FFPE tissue would allow one to take advantage of the huge amount of tissue samples stored in pathological institutes. Specht et $\mathrm{al}^{1}$ investigated the expression of HER-2/neu mRNA in FFPE esophageal adenocarcinomas. Tumors having a HER-2/ neu amplification and a 3+ EGFR immunohistochemistry were microdissected and HER-2/neu mRNA was quantitated. The data showed a large variability in HER-2/neu mRNA quantity. The large variation in HER-2/neu mRNA expression may reflect the heterogeneous mRNA expression levels throughout a tumor specimen, where HER-2/ neu positive cell clusters have been arbitrarily microdissected and analyzed. However, it cannot be excluded that fixation parameters such as fixation delay, time, and temperature may account for the large expression variability. Frozen sections were not included in the study to test differences due to fixation parameters.

Taken together, the authors present very important improvements for the RNA extraction from FFPE tissue and subsequent quantitation using TaqMan methodology. We still think that a fully controlled standardization of tissue fixation and processing, including testing for RNA quality prior to qualitative analysis, is a prerequisite for accurate gene expression measurement in FFPE tissue and at the same time insures comparative immunohistochemistry analysis. 
Daniel D'Orazio

Michael Stumm

Cornel Sieber

University Hospital Basel

Basel, Switzerland

\section{References}

1. Specht K, Richter T, Müller U, Walch A, Werner M, Höfler H: Quantitative gene expression analysis in microdissected archival formalinfixed and paraffin-embedded tumor tissue. Am J Pathol 2001, 158: 419-429

2. Shibutani M, Uneyama C, Miyazaki K, Toyoda K, Hirose M: Methacarn fixation: a novel tool for analysis of gene expression in paraffinembedded tissue specimen. Lab Invest 2000, 80:199-208

3. Heid CA, Stevens J, Livak KJ, Williams PM: Real-time quantitative PCR. Genome Res 1996, 6:986-994

4. D'Orazio D, Stumm M, Sieber C: Zonal gene expression in the human colon assessed by laser microdissection (OMD) and quantitative real-time RT-PCR. Gastroenterology 2002 (in press)

5. Kiernan JP: Histological and Histochemical Methods, Theory, and Practice, ed 3. Oxford, Butterworth-Heinemann, 1999

\section{Microsatellite Instability in Colorectal Cancer: Prognostic, Predictive or Both?}

\section{To the Editor-in-Chief:}

Guidoboni et $\mathrm{al}^{1}$ recently described favorable clinical outcome for proximally-located colorectal cancers (CRC) showing microsatellite instability $(\mathrm{MSI}+)$. This is in agreement with some ${ }^{2-4}$ but not all ${ }^{5,6}$ previous studies on the prognostic significance of this genetic alteration. Clarification is urgently required because of the possible consequences for selection of patients to receive adjuvant chemotherapy. Unfortunately, most of the studies to date have been difficult to interpret because of differences in MSI assessment criteria, as well as the use of mixed tumor stages, selected patient populations and adjuvant chemotherapy. For example, both the Guidoboni et $\mathrm{al}^{1}$ and an earlier study ${ }^{4}$ used the Bethesda criteria to define tumors as being MSI-H (high instability), yet the former report an incidence of $43 \%$ in proximal tumors compared to $25 \%$ for the latter.

We recently found that $\mathrm{MSI}+$, defined only as deletions in the mononucleotide repeat BAT-26, was prognostic for CRC patients treated by surgery and chemotherapy, but not for those treated with surgery alone. ${ }^{7}$ The first observation was subsequently confirmed by Hemminki et al. ${ }^{3}$ As with other studies, ${ }^{2,4-6}$ we compared the survival of $\mathrm{MSI}+$ patients to that of all MSI- patients. However, approximately $90 \%$ of sporadic $\mathrm{MSI}+$ tumors are found in the proximal colon, ${ }^{2-4,7}$ therefore the outcome of patients with these tumors should be compared to that of patients with MSI-proximal tumors, as in the report by Guidoboni et al. ${ }^{1}$ Multivariate analysis for factors affecting survival in stage III proximal tumors showed that MSI+ was a strong prognostic indicator for patients $(n=94)$ treated with chemotherapy $(\mathrm{RR}=0.15,95 \% \mathrm{Cl}:[0.04-0.64], P=$ $0.010)$ but not for those $(n=228)$ treated by surgery alone $(\mathrm{RR}=0.70,95 \% \mathrm{Cl}:[0.44-1.14], P=0.151) . \mathrm{A}$ trend for improved survival was evident in the latter group and therefore MSI status may show significant prognostic value when used in combination with activated cytotoxic lymphocyte counts. ${ }^{1}$

By comparing the survival of $\mathrm{CRC}$ patients treated with or without fluoropyrimidine-based (5FU) chemotherapy, we found that $\mathrm{MSI}+$ is a predictive factor for good survival benefit from chemotherapy. ${ }^{7,8}$ This finding is indirectly supported by observations made with the p53 tumor suppressor gene. CRC patients with wild-type, but not mutant $p 53$, gain significant survival benefit from chemotherapy. 8,9 Since almost all MSI+ tumors have wildtype $p 53,8,10$ it is perhaps not surprising that patients with these tumors should also show good survival benefit from chemotherapy. Validation of the predictive value of MSI+ should preferably be carried out in the context of prospective clinical trials that include adjuvant treatment and non-treatment arms. However, because of the widespread acceptance of 5FU in the treatment of stage III $\mathrm{CRC}$, it will be increasingly difficult to include non-treatment arms in future trials. Clinical trials of stage II CRC where patients are first stratified according to MSI status before randomization into treatment and non-treatment arms could be considered, although these will require larger numbers than for trials of state III CRC. Alternately, large retrospective studies that use defined MSI assessment criteria, tumor stage, patient characteristics, and adjuvant therapy status should allow comparison of survival rates between $\mathrm{MSI}+$ and $\mathrm{MSI}-$ proximal CRC patients (prognostic value) and between adjuvant-treated and non-treated $\mathrm{MSI}+$ cases (predictive value). Such studies should finally allow resolution of whether MSI+ in $\mathrm{CRC}$ is prognostic, predictive or, as we suspect, both.

\section{Marius van Rijnsoever Hany Elsaleh Barry lacopetta}

University of Western Australia

Nedlands, Australia

\section{References}

1. Guidoboni M, Gafa R, Viel A, Doglioni C, Russo A, Santini A, Del Tin L, Macri E, Lanza G, Boiocchi M, Dolcetti R: Microsatellite instability and high content of activated cytotoxic lymphocytes identify colon cancer patients with a favorable prognosis. Am J Pathol 2001, 159: 297-304

2. Gryfe R, Kim H, Hsieh ET, Aronson MD, Holowaty EJ, Bull SB, Redston M, Gallinger S: Tumor microsatellite instability and clinical outcome in young patients with colorectal cancer. N Engl J Med 2000, 342:69-77

3. Hemminki A, Mecklin JP, Jarvinen H, Aaltonen LA, Joensuu H: Microsatellite instability is a favorable prognostic indicator in patients with colorectal cancer receiving chemotherapy. Gastroenterology 2000, 119:921-928

4. Wright CM, Dent OF, Barker M, Newland RC, Chapuis PH, Bokey EL, Young JP, Leggett BA, Jass JR, Macdonald GA: Prognostic significance of extensive microsatellite instability in sporadically clniicopathological stage C colorectal cancer. Br J Surg 2000, 87:11971202

5. Feeley KM, Fullard JF, Heneghan MA, Smith T, Maher M, Murphy RP, 
O'Gorman TA: Microsatellite instability in sporadic colorectal carcinoma is not an indicator of prognosis. J Pathol 1999, 188:14-17

6. Salahshor S, Kressner U, Fischer H, Lindmark G, Climelius B, Pahlman L, Lindblom A: Microsatellite instability in sporadic colorectal cancer is not an independent prognostic factor. Br J Cancer 1999, 81:190-193

7. Elsaleh H, Joseph D, Grieu F, Zeps N, Spry N, lacopetta B: Association of tumour site and sex with survival benefit from adjuvant chemotherapy in colorectal cancer. Lancet 2000, 355:1745-1750

8. Elsaleh H, Powell B, McCaul K, Grieu F, Grant R, Joseph D, lacopetta B: p53 alteration and microsatellite instability have predictive value for survival benefit from chemotherapy in stage III colorectal carcinoma. Clin Cancer Res 2001, 7:1343-1349

9. Ahnen DJ, Feigl P, Quan G, Fenoglio-Preiser C, Lovato LC, Bunn Jr PA, Stemmerman G, Wells JD, Macdonald JS, Meyskens Jr FL: Ki-ras mutation and p53 overexpression predict the clinical behavior of colorectal cancer: a Southwest Oncology Group study. Cancer Res 1998, 58:1149-1158

10. Breivik J, Lotte RA, Meling GI, Rognum TO, Borresen-Dale AL, Gaudernack G: Different genetic pathways to proximal and distal colorectal cancer influenced by sex-related factors. Int J Cancer 1997, 74:664669

\section{Authors' Reply:}

The need for robust markers for a better prognostic definition of patients with colorectal cancer (CRC) has been increasingly pressing during the last decade. The introduction of adjuvant chemotherapy in the routine clinical management of patients with stage III CRC or in patients with high-risk stage II disease further enhanced the need for more precise prognostic indicators to efficiently direct the therapeutic choice. In the last years, several studies have investigated the prognostic significance of highfrequency microsatellite instability (MSI-H) in colon cancer, sometimes yielding conflicting results. ${ }^{1-5}$ Notwithstanding, the positive prognostic value of $\mathrm{MSI}-\mathrm{H}$ in $\mathrm{CRC}$ has been convincingly demonstrated by recent large population-based studies in which standardized criteria for MSI-H assessment have been used. ${ }^{4,5}$ Besides confirming the favorable clinical outcome of MSI-H CRC, our results also demonstrated that the prognostic value of the MSI status alone is significantly enhanced by the combined evaluation of the number of intratumoral-activated cytotoxic lymphocytes. ${ }^{6}$ This supports the hypothesis that MSI-H tumors may continuously produce new immunogenic epitopes as a consequence of the inherent defective DNA mismatch repair and may explain why patients with MSI-H CRC who are able to mount effective antitumor immune responses have a particularly favorable clinical outcome.

We fully agree with van Rijnsoever et al that MSI has relevant implications for the selection of CRC patients to receive adjuvant chemotherapy. Nevertheless, the putative role of MSI as a predictor of response to chemotherapy is still controversial. ${ }^{4,7,8}$ Our recent results do not seem to support such a generalized role, since the large majority $(79.8 \%)$ of patients from our series did not receive any additional therapy besides radical surgery, suggesting that adjuvant treatment could be useless in cases showing both MSI-H and high numbers of activated cytotoxic lymphocytes. ${ }^{6}$ On the other hand, adjuvant chemotherapy could be beneficial to those MSI-H cases (24\% in our series of proximal CRC) showing no evidence of local antitumor immune responses. In this respect, it should be considered that, besides direct cytotoxic activity, 5FU-based regimens may also have immunomodulatory effects that could contribute to enhance the responsiveness of this subset of tumors. ${ }^{9-10}$

As pointed out by van Rijnsoever et al, validation of the predictive value of MSI-H should require prospective clinical trials including adjuvant treatment and nontreatment arms. Nevertheless, due to the difficulties to include non-treatment arms in future trials, particularly in stage III CRC, as a first approach, we would favor the re-evaluation of large retrospective studies comprising both treated and non-treated arms, using standardized MSI assessment criteria, as well as defined tumor stage, patients' characteristics, and adjuvant therapy. In this respect, we also strongly recommend considering the number of activated cytotoxic lymphocytes infiltrating $\mathrm{CRC}$, which may allow a more precise assessment of the prognostic and, perhaps, the predictive value of MSI-H.

\section{Massimo Guidoboni \\ Alessandra Viel \\ Laura Del Tin \\ Mauro Boiocchi \\ Riccardo Dolcetti}

Centro di Riferimento Oncologico

Aviano, Italy

Roberta Gafa

Giovanni Lanza

University of Ferrara

Ferrara, Italy

Claudio Doglioni

Ettore Macri

City Hospital

Belluno, Italy

Centro per lo Studio e la Prevenzione Oncologica

Antonio Russo

Firenze, Italy

S. Anna Hospital

Alessandra Santini

Ferrara, Italy

\section{References}

1. Feeley KM, Fullard JF, Heneghan MA, Smith T, Maher M, Murphy RP, O'Gorman TA: Microsatellite instability in sporadic colorectal carcinoma is not an indicator of prognosis. J Pathol 1999, 188:14-17

2. Salahshor S, Kressner U, Fischer H, Lindmark G, Climelius B, Pahlman L, Lindblom A: Microsatellite instability in sporadic colorectal cancer is not an independent prognostic factor. Br J Cancer 1999, 81:190-193

3. Wright CM, Dent OF, Barker M, Newland RC, Chapuis PH, Bokey EL, Young JP, Leggett BA, Jass JR, Macdonald GA: Prognostic significance 
of extensive microsatellite instability in sporadically clniicopathological stage C colorectal cancer. Br J Surg 2000, 87:1197-1202

4. Halling KC, French AJ, McDonnell SK, Burgart LJ, Schaid DJ, Peterson BJ, Moon-Tasson L, Mahoney MR, Sargent DJ, O'Connell MJ, Witzig TE, Farr Jr GH, Goldberg RM, Thibodeau SN: Microsatellite instability and $8 p$ allelic imbalance in stage B2 and C colorectal cancers. J Natl Cancer Inst 1999, 91:1295-1303

5. Gryfe R, Kim H, Hsieh ET, Aronson MD, Holowaty EJ, Bull SB, Redston M, Gallinger S: Tumor microsatellite instability and clinical outcome in young patients with colorectal cancer. N Engl J Med 2000, 342:69-77

6. Guidoboni M, Gafa R, Viel A, Doglioni C, Russo A, Santini A, Del Tin L, Macri E, Lanza G, Boiocchi M, Dolcetti R: Microsatellite instability and high content of activated cytotoxic lymphocytes identify colon cancer patients with a favorable prognosis. Am J Pathol 2001, 159:297-304
7. Hemminki A, Mecklin JP, Jarvinen H, Aaltonen LA, Joensuu H: Microsatellite instability is a favorable prognostic indicator in patients with colorectal cancer receiving chemotherapy. Gastroenterology 2000, 119:921-928

8. Elsaleh H, Joseph D, Grieu F, Zeps N, Spry N, lacopetta B: Association of tumour site and sex with survival benefit from adjuvant chemotherapy in colorectal cancer. Lancet 2000, 355:17451750

9. Nichols PH, Ward U, Ramsden CW, Primrose JN: The effect of 5-fluorouracil and alpha interferon and 5-fluorouracil and leucovorin on cellular anti-tumour immune responses in patients with advanced colorectal cancer. Br J Cancer 1994, 70:946-949

10. Zagozdzon R, Golab J: Immunomodulation by anticancer chemotherapy: more is not always better (review). Int J Oncol 2001, 18:417-424 